\title{
Characterization of IpaH2 gene corresponding to lipopeptide synthesis in Bacillus amyloliquefaciens HAB-2
}

\author{
Pengfei Jin, Haonan Wang, Wenbo Liu and Weiguo Miao*
}

\begin{abstract}
Background: Bacillus spp. have prominent ability to suppress plant pathogens and corresponding diseases. Previous analyses of Bacillus spp. revealed numerous gene clusters involved in nonribosomal synthesis of cyclic lipopeptides with distinct antimicrobial action. The 4'-phosphopantetheinyl transferase (PPTase) encoded by sfp gene is a key factor in lipopeptide synthesis in Bacillus spp. In previous study, B. amyloliquefaciens strain HAB-2 was found to inhibit a broad range of plant pathogens, which was attributed to its secondary metabolite lipopeptide.

Results: A sfp homologue IpaH2 which encoded phosphopantetheinyl transferase but shared $71 \%$ sequence similarity was detected in strain HAB-2. Disruption of IpaH2 gene resulted in losing the ability of strain HAB-2 to produce lipopeptide, as well as antifungal and hemolytic activities. When IpaH2 replaced sfp gene of $B$. subtilis strain 168, a non-lipopeptide producer, the genetically engineered strain 168 could produced lipopeptides and recovered antifungal activity. Quantitative PCR assays indicated that, the expression level of IpaH2 in B. subtilis 168 strain decrease to 0.27-fold compared that of the wild type B. amyloliquefaciens strain HAB-2.
\end{abstract}

Conclusion: Few studies have reported about lpa gene which can replace sfp gene in the different species. Taken together, our study showed for the first time that IpaH2 from B. amyloliquefaciens could replace sfp gene.

Keywords: $s f p, I p a H 2$, Antimicrobial activity, Phosphopantetheinyl transferase

\section{Background}

Bacillus spp. such as B. amyloliquefaciens, and B. subtilis, have prominent ability to suppress plant pathogens and corresponding diseases [1]. Some Bacillus spp. strains have been commercialized for disease control [2]. These beneficial bacteria can produce a wide variety of bioactive secondary metabolites [3], the majority of which belong to lipopeptide family, including surfactin, iturin and fengycin [4]. These compounds play an important role in their antimicrobial activities as well as suppressing plant diseases [5]. Surfactin contributes in disturbing biofilm formation, and is endowed with antiviral and antimycoplasma activities for clinical applications [6-10]; iturin displays antifungal and hemolytic activities with limited antibacterial activities [11]; fengycin has strong inhibition against filamentous fungi [12].

\footnotetext{
* Correspondence: miao@hainu.edu.cn

Institute of Tropical Agriculture and Foresty, Hainan University, Hainan, China
}

More recently, much research has gone into establishing lipopeptide synthesis genes, and the complete genome sequences of Bacillus strains provide a powerful tool for finding the functional genes [13].

Depending on specific Bacillus strains, the regulation of lipopeptide production may vary [4]. Bacillus species are well-known for antibiotics peptides production which are the most important bioactive metabolites via a series of modules mega-enzymes called non-ribosomal peptide synthetases (NRPSs) [14, 15]. In Bacillus, the genes corresponding to biosynthesis of cyclic lipopeptides are assembled as large gene clusters, which encode large multifunctional enzyme complexes, or NRPSs [1]. To synthetize cyclic lipopeptides, NRPSs possess a multidomain structure and affect the ordered recognition, activation, and linking of amino acids by utilizing the thiotemplate mechanism [16]. NRPSs also require posttranslational modification to be functionally active by 4'-phosphopantetheinyl transferase (PPTase) [17], 
which is encoded by $s f p$ gene. This can be confirmed by that the model system $B$. subtilis 168 has the entire gene clusters for synthesizing surfactin and fengycin. However, due to the absence of $s f p$ gene, these two lipopeptides are not produced [18]. Another example is that disruption of $s f p$ gene of $B$. amyloliquefaciens FZB42 abolished the production of lipopeptides [19]. Furthermore, a native $s f p$ gene was transferred into $B$. subtilis 168, which could restore the production of fengycin and surfactin lipopeptides [20]. Roongsawang et al. demonstrated that $s f p$ has broad substrate preferences that allow posttranslational modification of both peptidyl carrier protein in the nonribosomal peptide synthetases and the acyl carrier protein [21]. All of these evidences indicate that $s f p$ is indispensable in synthesis of lipopeptides.

In the previous study, strain HAB-2 was isolated from the rhizosphere soil of cotton plant and it showed strong antifungal activity [22]. MALDI-TOF MS and PCR analysis showed that strain HAB-2 lacked $s f p$ gene although it could produce surfactin and iturin lipopeptides. Accordingly, we determined the role of lpaH2 gene from strain HAB-2 in B. amyloliquefaciens and B. subtilis, based on the deletion of lpaH2 from strain HAB-2 and complementation of lpaH2 into the wild-type B. subtilis 168 .

\section{Methods}

\section{Bacterial and fungal cultures}

Test organisms and plasmids used in this study are listed in the Table 1. The strain HAB-2 was isolated in the author's laboratory from cotton field soil in Xinjiang Province, China and was deposited in China Center for Type Culture Collection (CCTCC), with accession number of ID.CCTCC M 2015070. All the Bacillus spp. cultures were routinely cultivated at $28{ }^{\circ} \mathrm{C}$ in Luria Bertani broth (LB) for $48 \mathrm{~h}$. Escherichia coli was routinely cultivated at $37{ }^{\circ} \mathrm{C}$ in $\mathrm{LB}$ broth for $24 \mathrm{~h}$. Potato dextrose agar (PDA) was used to culture Colletotrichum gloeosporioides.

\section{Morphological observation and molecular identification} The morphology of B. amyloliquefaciens was observed using scanning electron microscope (SEM). Prior to the observation, the cells of strain HAB-2 were centrifuged and then prefixed with $2.5 \%$ glutaraldehyde. The treated bacterial cells were rinsed three times each for $10 \mathrm{~min}$ with $100 \mathrm{mM}$ phosphate buffer, post fixed for $3 \mathrm{~h}$ in $1 \%$ osmium tetroxide, and dehydrated through ethanol gradient. The samples were coated with gold and analyzed on Hitachi S-3000 N SEM (Hitachi, Japan). Micrographs were taken at $10.0 \mathrm{kV}$ [23].

The chromosomal DNA of strain HAB-2 was extracted using Bacterial Genomic DNA Extraction Kit (Tiangen Biochemical Science and Technology Co., LTD) according to the manufacturer's protocol. The $16 \mathrm{~S}$ rRNA gene was amplified using PCR, with primer pair 27F/1492R (27F: 5'-AGAGTTTGATCATGGCTCAG3'; 1492R: 5'-GGTTACCTTGTTACFACTT-3') using the following program: pre-denaturation at $94{ }^{\circ} \mathrm{C}$ for $5 \mathrm{~min}, 35$ cycles of amplification at $94{ }^{\circ} \mathrm{C}$ for $1 \mathrm{~min}, 50^{\circ}$ $\mathrm{C}$ for $31 \mathrm{~min}$, and $72{ }^{\circ} \mathrm{C}$ for $2 \mathrm{~min}$, and a final extension at $72{ }^{\circ} \mathrm{C}$ for $10 \mathrm{~min}$ [24]. The obtained sequences were analyzed using BLAST program of NCBI. The sequence alignment (produced using Clustal W) was imported into the program MEGA5, and the phylogenetic tree was constructed using the neighbor-joining method with 1000 bootstrap replicates.

\section{In vitro assay of antagonism}

B. amyloliquefaciens strain HAB-2 was assayed for antagonism against 17 strains of plant pathogenic fungi (Additional file 1: Table S1). These pathogenic fungi were transferred onto the center of a PDA plate, and four culture plugs of $B$. amyloliquefaciens strain HAB-2 were placed near the edge of the same plate with same distance each other. The co-inoculated cultures were incubated at $28{ }^{\circ} \mathrm{C}$ for $72 \mathrm{~h}$. Antifungal activity was determined by measuring growth inhibition by HAB-2. The inhibitory rate of mycelial growth $(\%)=(\mathrm{AB}-\mathrm{Aa}) /$ $A B \times 100 \%$ where $A a$ is the diameter of fungal colony on the line between fungal and bacterial inoculation pints,

Table 1 Organisms and plasmids used in this study

\begin{tabular}{|c|c|c|}
\hline Organisms and plasmids & Description & Source \\
\hline Escherichia coli DH5a & SupE44 $\triangle$ lacU $169 \varnothing 80$ lacZ $\triangle$ M15 hsdR17 recA1 gyrA96 thi-1 relAF ${ }^{-}$ & Transgen Bio Inc. \\
\hline Bacillus amyloliquefaciens HAB-2 & IpaH2 gene, wild type, produces lipopeptides & Collection of this lab \\
\hline Bacillus amyloliquefaciens $\mathrm{HAB} \Delta / p a$ & deficient in lipopeptides; $\mathrm{Cm}^{r}$, Amp ${ }^{r}$ & This work \\
\hline Bacillus subtilis 168 & deficient in lipopeptides & Collection of this lab \\
\hline Bacillus subtilis 168 Ipa & IpaH2 gene, can produce lipopeptides; $\mathrm{Cm}^{r}$, Amp ${ }^{r}$ & This work \\
\hline Colletotrichum gloeosporioides & Indicator strain, causative agent of mango anthracnose & Collection of this lab \\
\hline pAD 43-25 plasmid & Shuttle vector carrying GFP; $\mathrm{Cm}^{\mathrm{r}}$ & Collection of this lab \\
\hline pMD18-T plasmid & T-clone site vector; lacZ; $\mathrm{Amp}^{\mathrm{r}}$ & TaKaRa Bio Inc. \\
\hline
\end{tabular}

$A m p^{r}$ ampicillin resistance, $\mathrm{Cm}^{r}$ chloramphenicol resistance, GFP green fluorescent protein 
and $A B$ is the diameter of fungal colony without bacterial inoculation. Each treatment had three replicates.

\section{Bioassay analysis of lipopeptides from $B$. amyloliquefaciens strain HAB-2}

B. amyloliquefaciens strain HAB-2 was cultured in LB broth at $28{ }^{\circ} \mathrm{C}$ for $48 \mathrm{~h}$ under $170 \mathrm{rpm}$ shaking. The culture medium was reduced in vacuo at $55{ }^{\circ} \mathrm{C}$, and metabolites in the concentrated medium were extracted with n-butyl alcohol three times at $28^{\circ} \mathrm{C}$. The combined extracts were then concentrated in vacuo to dryness. The antifungal activity of lipopeptides was tested against C. gloeosporioides using paper disc method. C. gloeosporioides was inoculated into carboxymethylcellulose sodium (CMC) medium and grown for 3 days at $28{ }^{\circ} \mathrm{C}$. The fermented liquid then filtered through 4 consecutive sterile absorbent cotton wool plugs to remove any hyphal fragments. The number of spores was counted using a hemocytometer, diluted to $10^{6}$ spores $/ \mathrm{mL}$. An aliquot of $4 \mathrm{mg} / \mathrm{L}$ lipopeptides was impregnated on a sterile filter paper discs (6 $\mathrm{mm}$ diameter), aseptically applied to the surface of an agar plate. Then the diameters of inhibition zones were measured after $48 \mathrm{~h}$. The experiment was performed in triplicate.

\section{Chemical analysis of lipopeptides from strain HAB-2}

Matrix-assisted laser desorption ionization-time of flight (MALDI-TOF) mass spectra was employed to analyze lipopeptides in HAB-2. The culture filtrate of HAB-2 was acidified to $\mathrm{pH} 2$ with $6 \mathrm{~N} \mathrm{HCl}$ and stored at $4{ }^{\circ} \mathrm{C}$ overnight, and then centrifuged. The precipitate was dissolved in methanol and filtered through a $0.2 \mu \mathrm{m}$ polytetrafluoroethylene membrane. The experiment was conducted by means of a Bruker Daltonics Reflex MALDI-TOF mass spectrometer with a Scout-mtp ion source containing a $337 \mathrm{~nm}$ nitrogen laser. All spectra were acquired in the reflector positive ion mode. The acceleration and reflector voltages were $25 \mathrm{kV}$ and $26.3 \mathrm{kV}$ respectively. The matrix medium was a saturated solution of a-cyano-4-hydroxycinnamic acid in $30 \%$ aqueous acetonitrile containing $0.1 \%$ trifluoroacetic acid $(v / \mathrm{v})$. For MALDI-TOF analysis, $1 \mu \mathrm{L}$ extract was added onto the target plate, with $1 \mu \mathrm{L}$ working solution, and then air dried.

\section{Transformation and DNA manipulation}

Plasmids were extracted and purified using Omega Plasmid Miniprep Kit (Omega Bio-Tek, Norcros, GA, USA) following the manufacturer's protocol. The genomic DNA was isolated using the Bacterial Genomic DNA Extraction Kit (Tiangen Biochemical Science and Technology Co., Ltd., Beijing, China) according to the manufacturer's protocol. E. coli cell transformations were performed as described by Sambrook [25]; B. subtilis and B. amyloliquefaciens cells were transformed according to the method of Anagnostopoulos and Spizizen [26].

\section{Detection of lipopeptide and nonribosomal peptide synthetase genes}

The synthetase and regulatory genes of lipopeptides including ituC, srfAB, sboA, ituD, qk, fenD, bamC, yndj, $i t u B$, fenB, ituA, lpa and sfp (Additional file 1: Table S2), were amplified by PCR using specific primers which were designed on the basis of published genome sequences of B. subillis 168 (accession number CP019662.1), B. subillis RB14 (accession number D21876.1), and B. amyloliquefaciens FZB42 (accession number CP000560.1).

\section{Southern-blot hybridization}

To confirm whether strain HAB-2 and 168 have lpa and sfp genes, Southern-blot hybridization analysis was carried out. The chromosomal DNA of strains HAB-2 and 168 were digested by EcoRIand Rsalenzymes, then resolved on a $1 \%$ agarose gel by electrophoresis and transferred to a positively charged Nylon membrane (Roche Molecular Biochemicals, Mannheim, Germany). Southern-blot analysis was performed using the digoxigenin (DIG) DNA Labeling and Detection Kit (Roche Molecular Biochemicals, Germany) with $s f p$ and lpa genes as a probe, according to the manufacturer's protocol.

\section{Mutants and revertants construction}

Recombination flanks were amplified by PCR. The upstream and downstream flanks were obtained using chromosomal DNA of B. amyloliquefaciens HAB-2 with the primer pairs F1/F2 and F5/F6, respectively (Additional file 1: Table S3). The chloramphenicol resistance gene fragment was amplified from $\mathrm{P} 43-25$ plasmid using with primers F3/F4 (Additional file 1: Table S3) by filling in the overlaps. The two gelpurified fragments were linked by $\mathrm{Cmr}$ resistance cassette and then cloned into plasmid pMD-18. The plasmid pMD18-T was transformed into the competent cells of strain HAB-2 and cells were plated on LB agar plates containing chloramphenicol, which were identified by testing for sensitivity against chloramphenicol. There were 176 mutants screened and isolated on a LB agar plate containing ampicillin and chloramphenicol, and transgenic positive mutants were verification by PCR with primers JD1 and JD2 (Additional file 1: Table S3).

To determine the effect of lpaH2 gene on lipopeptide synthesis, lpaH2 and chloramphenicol-resistant cassette were transformed into wild-type $B$. subtilis 168. For complementation analysis of lpaHAB-2 in $B$. sublilis 168 , the recombination flank fragments were amplified by PCR with the primer pairs J1/J2 and J7/J8, respectively (Additional file 1: Table S3). 
Amplification of lpaH2 gene was carried out with primers $\mathrm{J} 3 / \mathrm{J} 4$ and chloramphenicol gene from carrier plasmid (P43-25) was amplified with primers J5/J6 (Additional file 1: Table S3). Using fusion PCR, these fragments were linked and cloned into the vector pMD18-T and were transformed into the competent cells of B. subtilis 168 with the integration vector pMD18-T. The live mutants were isolated on a LB agar plate containing ampicillin and chloramphenicol, and transgenic positive mutants were verification with primers JD3 and JD4 (Additional file 1: Table S3).

To analyze the phenotype, spore suspension of $C$. gloeosporioides was spread on agar plate, followed by placing bacterial colony on the plate. Antifungal activities of bacterial strains were determined by measuring the inhibiting zone on C. gloeosporioides. The hemolysis activity of bacteria was tested on a blood agar plate.

\section{RNA extraction and qRT-PCR}

The primers were designed by using Primer Premier 5.0 based on the sequence of lpaH2 (GenBank: KX592168.1). Primer specificity was confirmed by agarose gel electrophoresis and melting curve analysis. The expression of lpaH2 gene was monitored with qRT-PCR. The $16 S$ rRNA gene was used as the internal reference. The gene primers were listed in Additional file 1: Table S2. The 168lpa mutants and the wild type strain $\mathrm{HAB}-2$ as control were cultured for $48 \mathrm{~h}$. The RNAs were extracted following the RNAprep prue KIT (Tiangen) and complementary DNA (cDNA) was synthesized with the Prime Script RT-PCR kit (TaKaRa, Japan). The qRT-PCR assay used SYBR Premix EX Taq kit (TaKaRa) in $20 \mu \mathrm{L}$ on the ABI Prism 7500 system. The program consisted of a Hot-Start activation step at $95{ }^{\circ} \mathrm{C}$ for $14 \mathrm{~s}$, followed by 40 cycles of: $95{ }^{\circ} \mathrm{C}$ for $15 \mathrm{~s}, 56{ }^{\circ} \mathrm{C}$ for $30 \mathrm{~s}, 72{ }^{\circ} \mathrm{C}$ for $30 \mathrm{~s}$. The experiment was repeated three times and the data were normalized according to the $2^{-\triangle \Delta C T}$ method.

\section{Results}

Morphology and identification of $B$. amyloliquefaciens HAB-2 The cells of strain HAB-2 were intact, plump, and rodshaped (Additional file 1: Figure S1). Sequence alignment showed that 16S rRNA gene of HAB-2 shared 99\% similarity with that of $B$. amyloliquefaciens strain $\mathrm{YH}-22$ (GenBank accession number KF797461.1) and 99\% similarity with $B$. amyloliquefaciens subsp. plantarum FZB42 ${ }^{\mathrm{T}}$ (GenBank accession number CP000560.1) (Fig. 1). Based on these results, the strain HAB-2 was preliminary identified as B. amyloliquefaciens (GenBank accession number KX600493).

\section{Analysis of lipopeptides, their antifungal acitivites, and related genes in HAB-2}

B. amyloliquefaciens HAB-2 has antifungal activity to inhibit the growth of all test organisms with inhibition rates ranging from 42.99 to $69.76 \%$ on agar plates (Additional file 1: Table S3). The MALDI-TOF MS analysis is a convenient and efficient way to monitor qualitative results for lipopeptides in crude extracts which yielded complementary result. Using MALDITOF MS, several groups of mass signals were observed with the peaks at $\mathrm{m} / \mathrm{z}=928.868,953.705,999.465$, 1020.729, 1042.038, 1057.485 and 1116.515 (Fig. 2 and Additional file 1: Table S4) [27, 28]. The result suggested that these peaks could be attributed to the isoform ensembles of surfactins and iturins [29], which provided a theoretical basis for the following studies.

Genes associated with the biosynthesis of lipopeptides in strain HAB-2 were cloned and sequenced. Genes such as $\operatorname{srfAB}$ (segment of $308 \mathrm{bp}$ ), ituD (647 bp), fenD (293 bp), bamC (850 bp), yndj (212 bp), ituB (508 bp) and ituA (885 bp) from HAB2 could be amplified and had high degree of similarity to homologous sequences (Additional file 1: Figure S2), ranging from 97 to 99\% (NCBI GenBank accession number DQ977668.1, HQ711614.1, DQ977668.1, CP006890.1, DQ977671.1, JN093026.1 and EU263005, respectively). ituC, $q k, f e n B$ genes could not amplified

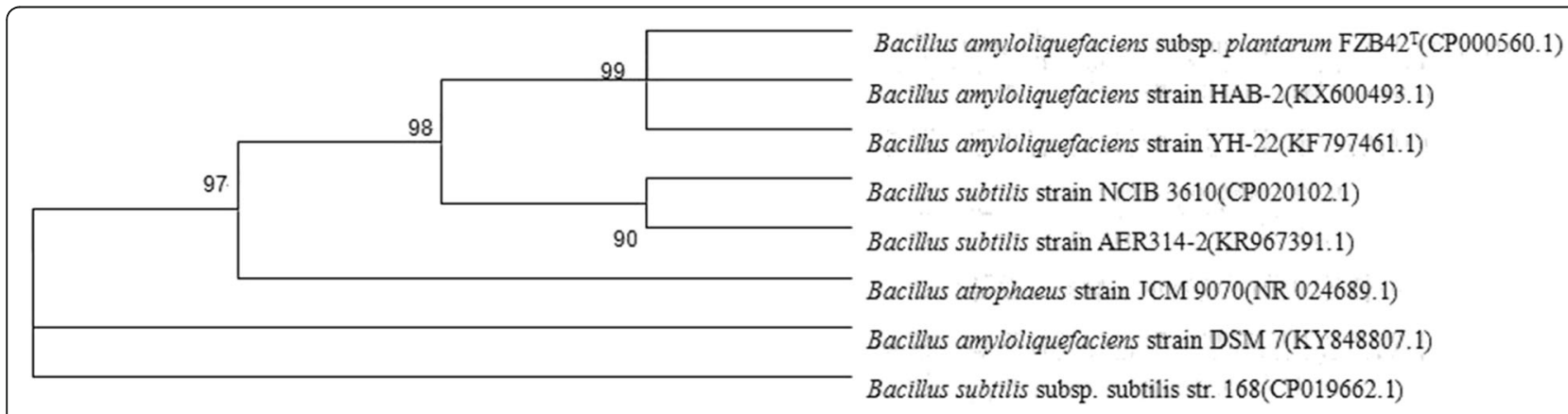

Fig. 1 Phylogenetic tree constructed based on 165 rRNA sequences of HAB-2 and Bacillus spp. (16S rRNA sequences of strains retrieved from the NCBI GenBank. Bootstrap values were expressed as \% of repetitions at branching points) 


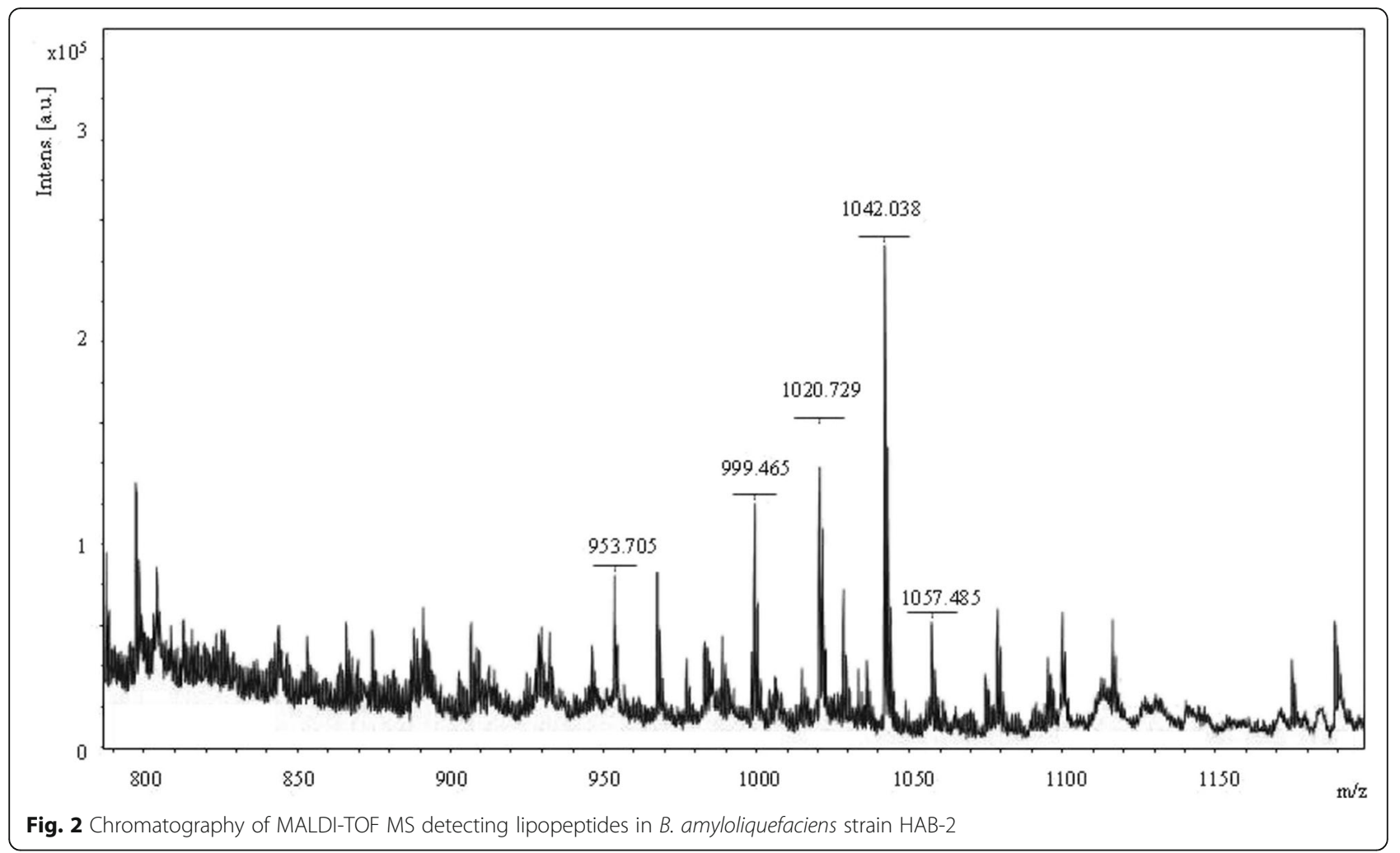

from strain HAB-2. This suggested that HAB-2 had the potential of producing lipopeptides including surfactins, fengycins, iturins, and bacillomycins.

Only lpa gene (675 bp) was detected in strain HAB-2, in contrast, $s f p$ gene $(675 \mathrm{bp})$ was amplified in strain 168
(Fig. 3a). Sequence analysis indicated that lpa fragment from strain HAB-2 shared $99 \%$ similarity with B. subtilis RB14 (D21876.1). This fragment was accordingly named as lpaH2 (Accession KX592168) in strain HAB-2. A panel in Fig. 3b shows the signal for the lpa fragment in
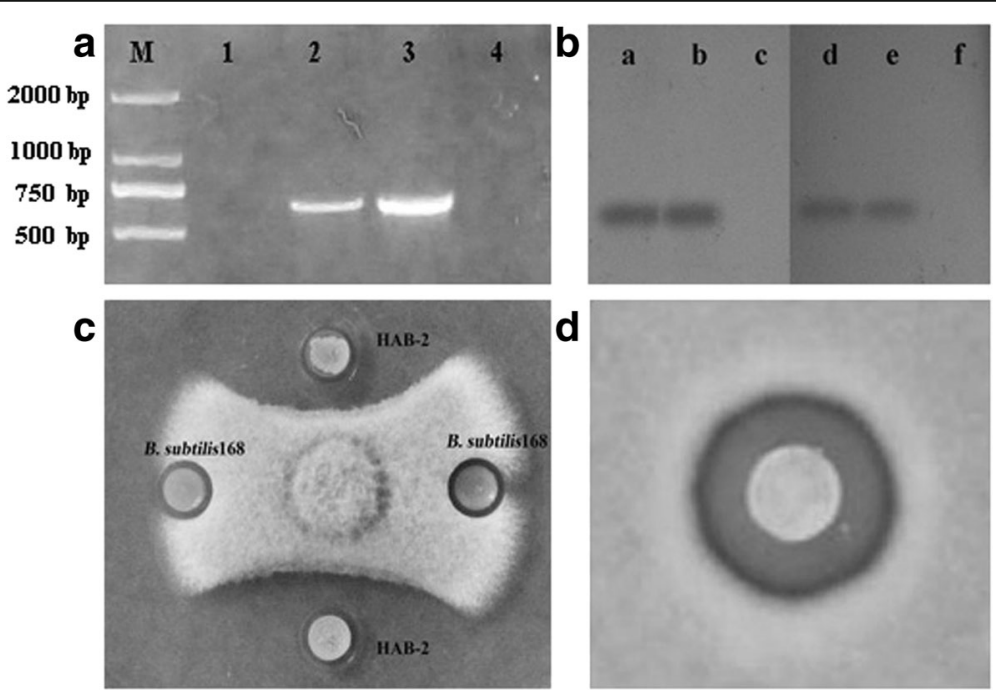

Fig. 3 Lipopeptide analysis from B. amyloliquefaciens HAB-2 and B. subtilis 168. a Amplification of Ipa and sfp gene fragments from B. amyloliquefaciens HAB-2 and B. subtilis 168. From lane 1 to 4: HAB-2-sfp; B. subtilis 168-sfp; HAB-2-Ipa; and B. subtilis 168-Ipa. Lane M: 2000 bp DNA marker. b Southern-blot hybridization for IpaH2 and sfp genes, a: Ipa from the strain HAB-2, b: chromosomal DNA of the strain HAB-2, c: chromosomal DNA of B. subtilis 168, d: sfp from B. subtilis 168, e: chromosomal DNA of B. subtilis 168, f: chromosomal DNA of the strain HAB-2. c Antifungal activity of B. amyloliquefaciens HAB-2 and B. subtilis 168 against C. gloeosporioides on agar plate. $\mathbf{d}$ Inhibitory effect of lipopetides produced from B. amyloliquefaciens HAB-2 against C. gloeosporioides 
strain HAB-2. As expected, one signal was identified for the $s f p$ gene fragment in strain 168. The southern hybridization results demonstrated that strain HAB-2 genome contains lpa gene but lacks $s f p$ gene (Fig. 3c). Bioassays showed that $s f p$-inactive strain B. subtilis 168 did not inhibit the growth of $C$. gloeosporioides but strain HAB-2 did (Fig. 3d). HAB-2-derived lipopeptides at the concentration of $4 \mathrm{mg} / \mathrm{L}$ exhibited an antifungal activity with an inhibitory zone of $12.2 \pm 0.1 \mathrm{~mm}$ (Fig. 3e). Lpa family demonstrated high homology and a similar organization to Sfp family which encoded 4'-phosphopantetheinyl transferase [30]. The lpa gene of strain HAB-2 shared $71 \%$ amino acid identity with $s f p$ of $B$. subtilis 168 (Fig. 4) Generally, sfp is recognized as essential element for activation of lipopeptides formation. Therefore, we proposed that lpa of strain HAB-2 plays critical roles in lipopeptides formation [19].

Examining the biological function of $\mathrm{IpaH} 2$ gene by deletion The plasmid pMT-18 was constructed for deletion of lpa gene from strain HAB-2. Double crossover homologous recombination resulted in the deletion of a $0.6-\mathrm{kb}$ lpa fragment and was replacement with chloramphenicol (Cmr)-resistance cassette on the chromosome. Two primers amplified the segment containing the genes to facilitate identification of positive transformants and $\mathrm{Cmr}$ transformants were selected. Disruption of lpaH2 derived from the strain HAB-2 was documented. The transformation resulted in mutants carrying plasmid pMT-18 (Fig. 5a). The fragment linked $\mathrm{Cm}$-resistant and lpaH2 genes ( $2.5 \mathrm{~kb}$ in size) were detected. The effect of the $\mathrm{HAB} \triangle l p a$ mutant on lipopeptide synthesis was monitored by growth inhibition of $C$. gloeosporioides. The results demonstrated that wild-type strain $\mathrm{HAB}-2$ has inhibition ability, in the contrast antimicrobial actions of the $\mathrm{HAB}^{\circ} l p a$ mutants were abolished (Additional file 1: Figure S3A and B). Compared to the wild-type strain HAB-2, which had ability to lyse the blood cells by surface-active compounds and cause a halo on blood agar plate, the hemolytic activities of HAB-2 derivatives in the absence of lpaH2 were also abolished based on the observation of no halo (Additional file 1: Figure S3C and D). It suggests that strain HAB-2 derivatives in the absence of lpaH2 could not produce surfactin. Mass spectra data suggested that strain HAB-2 could produce lipopetides including iturin and surfactin (Fig. 2). However, the $\mathrm{HAB} \triangle l p a$ mutant had complete deficiency of lipopeptide production (Fig. 5b).

\section{Examining the biological function of $I p a H 2$ gene by complementation}

The lpaH2 gene was successfully integrated into the chromosome of B. subtilis 168 by homologous recombination (Fig. 6). The mutants have antifungal activity against C. gloeosporioides (Additional file 1: Figure S4A and B). Hemolytic activity of the 168lpa mutant was detected on blood agar plate (Additional file 1: Figure S4C and D), which was an evidence for surfactin production. Mass spectrum showed peaks at $\mathrm{m} / \mathrm{z}$ values 1008 and 1022, which could be attributed to the surfactin of the extract of the 168lpa mutant (Fig. $6 \mathrm{~b}$ and c).

\section{Effect on IpaH2 gene expression}

Quantitative PCR assays indicated that the lpaH2 integrated into the $B$.subtilis 168 strain makes the expression level to decrease to 0.27 -fold of the wild type B. amyloliquefaciens strain HAB-2 (Fig. 7).

\section{Discussion}

We have demonstrated that strain HAB-2 was most closely related to $B$. amyloliquefaciens subsp. plantarum FZB42 ${ }^{\mathrm{T}}$. Based on the production of liquefying amylase, $B$. amyloliquefaciens was added as its own distinct species in 1987 [31]. B. amyloliquefaciens subsp. plantarum was in

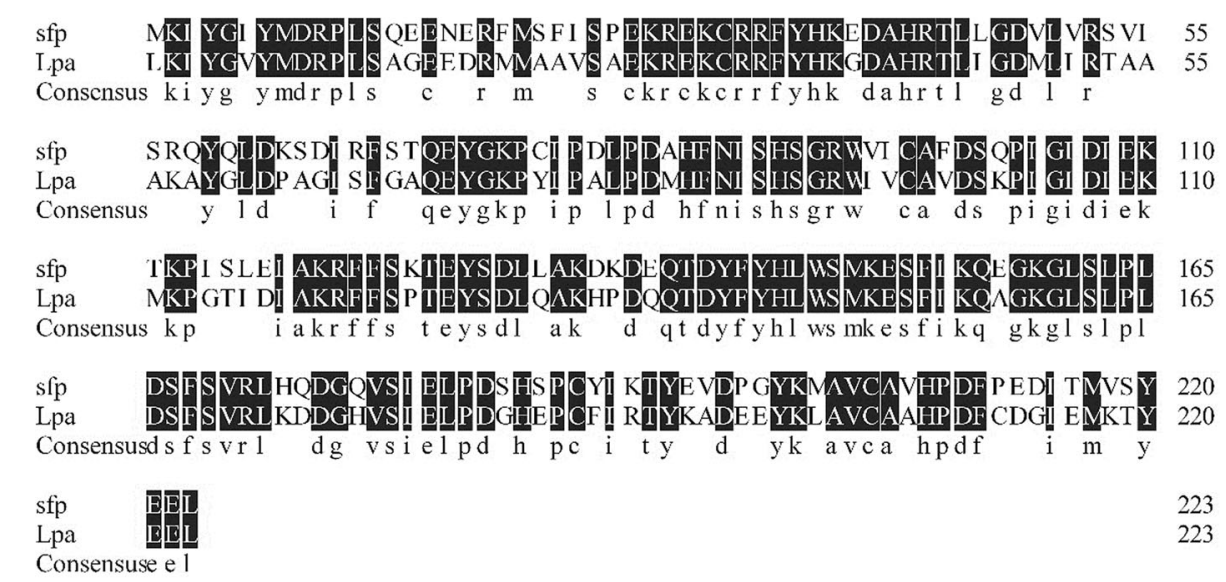

Fig. 4 Amino acid sequence alignments of Ipa in B. amyloliquefaciens HAB-2 and sfp of B. subtilis 168. (Highlighted letters indicate identity) 


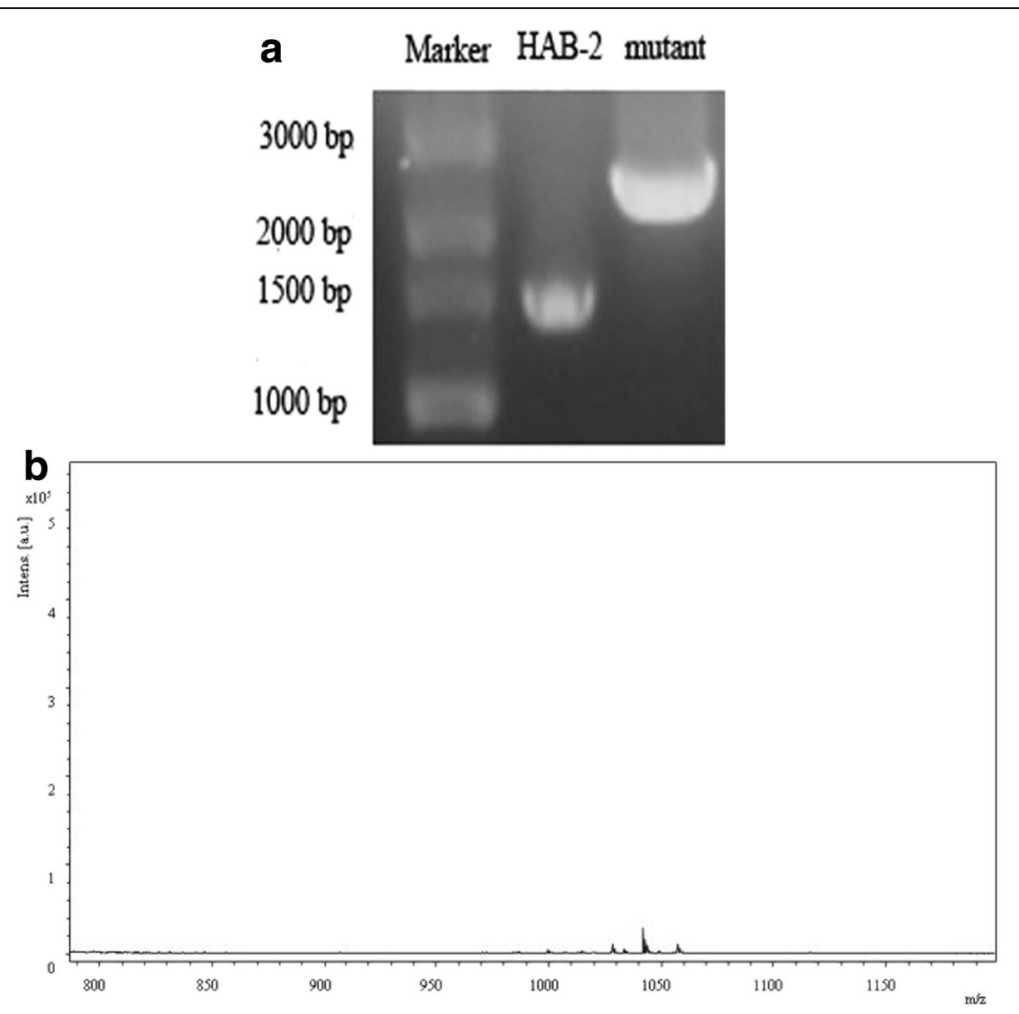

Fig. 5 Characterization of B. amyloliquefaciens strain HAB-2 and its mutant. a Gel electrophoresis of PCR products of wild-type strain HAB-2 (lane HAB-2) and its mutant (lane Mutant); b MALDI-TOF MS analysis on the extract of HAB $\triangle$ Ipa mutant, 3000 bp DNA marker

the clade of B. amyloliquefaciens and the genome of type strain FZB42 was revealed in 2007 [13]. However, recent research reported that $B$. amyloliquefaciens subsp. plantarum should be reclassified as later heterotypic synonyms of B. methylotrophicus KACC $13015^{\mathrm{T}}$ or B. velezensis NRRL B-41580 T [32, 33].

B. amyloliquefaciens HAB-2 had inhibitory activity against 17 plant pathogenic fungi when 7 lipopeptide synthetase genes, including ituB, $\operatorname{srf} A B$, ituD, fenD, yndj, ituA, bamC, were cloned from strain HAB-2. These lipopeptides of strain HAB-2 belonged to surfactin, iturins and fengycin families. As mentioned above, $s f p$ encodes PPTase which plays an essential role in priming synthases, NRPS, from inactive apo forms to active holo forms $[19,34,35]$. The non-lipopeptide-producer $B$. subtilis 168 has the peptide synthetase [36], due to a frameshift mutation in $s f p$ responsible for conversion of nascent antibiotic synthetases to active holoforms [11]. However, the strain HAB-2 also lacked $s f p$ gene whereas lipopeptides biosynthesis remained unimpaired. It suggests that strain HAB-2 has biosynthetic machinery for different lipopeptides production. From the amino acid sequence analysis, lpaH2 gene in the strain HAB-2 was identified and was similar to the $s f p$ gene. Some reports indicated that lpa gene showed 73\% homology with $s f p$ and is crucial to the regulation of surfactin and iturin A production in B. subtilis or B. pumilus [30, 37, 38]. Tsuge et al. demonstrated that lpa-8 is a regulatory protein that acts as a transcription initiation factor and is required for amino acid transfer, for peptide secretion, or for the transport system of the peptides [39]. Mutational analysis of $l p a H 2$ and the effect on corresponding lipopeptides production aided us in elucidating the function of lpaH2. We hypotheze that lpaH2 plays a similar role with $s f p$ gene in the synthesis of lipopeptides in HAB-2 strain. Thus, lpaH2 gene was knocked out in strain HAB-2 by double crossover homologous recombination with antibiotic and hemolytic activities abolished, as observed in B. subtilis 168. Our results also seem to support that lpaH2 has functional homology with $s f p$ gene. We tentatively conclude that $l p a H 2$ is responsible for activating lipopeptide synthases, which replaces the function of $s f p$ in strain HAB-2.

Sfp synthesizes bioactive peptides in plantdependent pathways of secondary metabolism of Bacillus spp. Li et al. [24] demonstrated that $B$. subtilis 168 genetically engineered with $s f p$ gene synthesized a large amount of surfactin. A similar observation has been reported that B. subtilis 168 derivatives introduced an intact copy of $s f p$ recovered production of polyketide bacillaene [40]. Furthermore, lpa-14 showed $72 \%$ homology with $s f p$, 


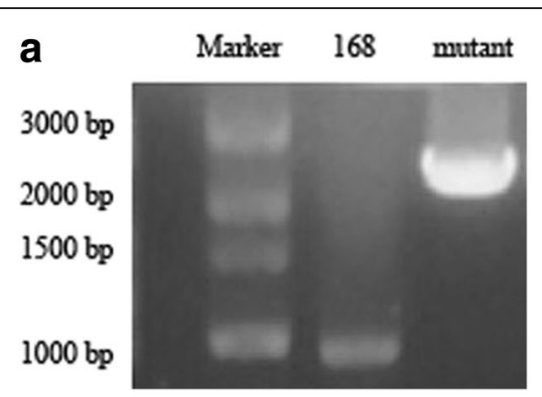

b

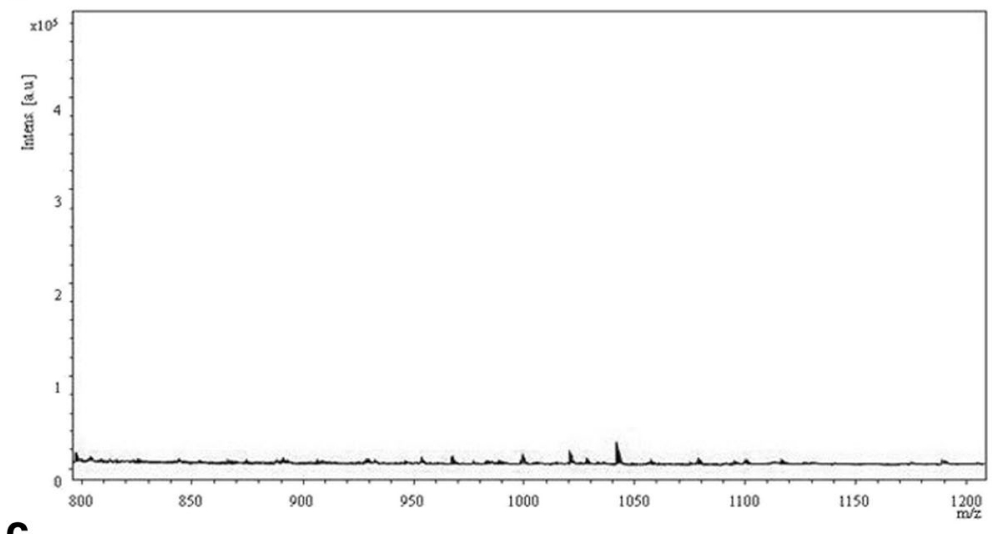

C

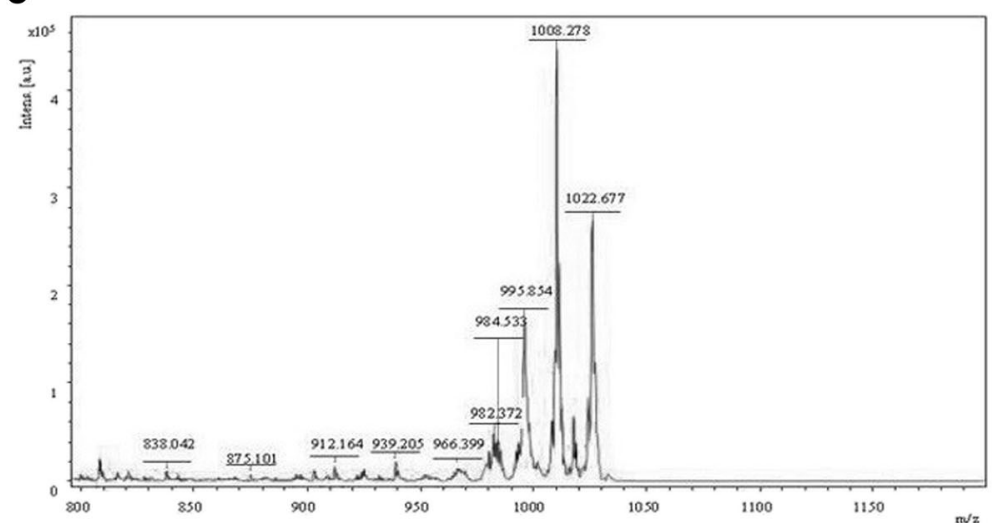

Fig. 6 Characterization of wild-type Bacillus subtilis stain 168 and its mutant. a Gel electrophoresis of PCR products of wild-type strain 168 (lane 168) and its mutant (lane Mutant); b MALDI-TOF-MS analysis on extracts of wild-type strain 168; c MALDI-TOF-MS analysis on the extract of strain 168 mutant, 3000 bp DNA marker

which is responsible for surfactin in B. subtilis RB14 convert B. subtilis 168 to a surfactin-producer [38, 41]. Tsuge et al. [20] revealed that B. subtilis 168 expressing only lpa-8 can produce plipastatin. Nevertheless, B. subtilis 168 by transformation of lpaB3, isolated from B. subtilis B3, could not produce iturin A [42]. It was suggested that lpaB3 gene possibly regulated biosynthesis surfactin in $B$. subtilis strain 168 [42], which explain lpa gene regulation varies in peptide antibiotics uniqueness among Bacillus species [38]. However, there have been few studies reported on lpa gene which can replace $s f p$ gene, especially between the $B$. subtilis and B. amyloliquefaciens strains. When
lpaH2 replaced sfp gene of B. subtilis strain 168, a nonlipopeptide producer, the genetically engineered strain 168 possessed antagonistic and hemolysis properties. Our study is the first time to investigate that lpaH2 from $B$. amyloliquefaciens could replace sfp gene and also played a major role in B. subtilis. Besides this, the inhibition of mutant has not increase significantly, which might be due to the transformation of the exogenous gene from B. amyloliquefaciens strain into B. subtilis. We suggest that it might be partly explained by the different similarity of $l p a H 2$ and $l p a$ with $s f p$, which is $72 \%$ or $73 \%$ homology with $s f p$ in the previous reports. The antifungal ability can be enhanced by increasing the strong promoter in subsequent experiments. 


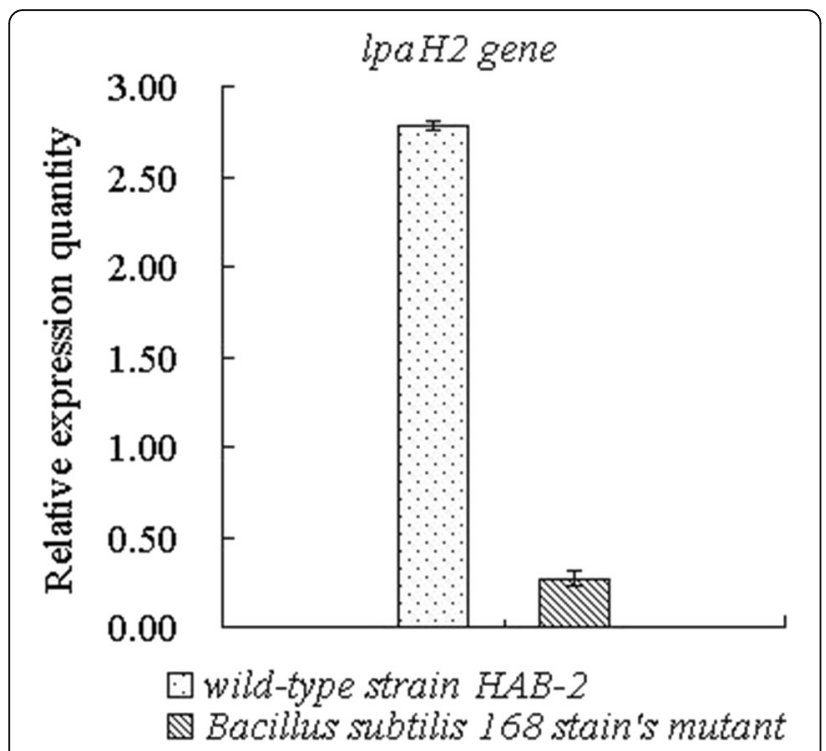

Fig. 7 The qRT-PCR analysis of expression of IpaH2 in B. subtilis 168 stain's mutant and wild-type strain HAB-2 at $48 \mathrm{~h}$. The values were normalized to the levels of $16 \mathrm{~S}$ rRNA, which is a housekeeping gene as an internal reference gene. The $y$-axis values represent the mean expression \pm the standard deviations $(n \geq 3)$ relative to the control

\section{Conclusions}

lpaH2 was equally important as $s f p$ gene in lipopeptide synthesis in B. amyloliquefaciens HAB-2. Our current work investigating the functions and relationships between Lpa and Sfp families will help to understand the evolutionary and genetic characteristics of these genes. Hence, further work will be necessary to understand that evolutive and genetical characteristics in Lpa family and Sfp family, individually or in combination, contributed to productions.

\section{Additional file}

Additional file 1: Characterization of $1 \mathrm{paH} 2$ gene corresponding to lipopeptide synthesis in Bacillus amyloliquefaciens HAB-2. (PDF $1085 \mathrm{~kb}$ )

\footnotetext{
Abbreviations

16S rRNA: 16S ribosomal RNA; Ampr: Ampicillin resistance; CCTCC: China Center for Type Culture Collection; CMC: Carboxymethylcellulose sodium; Cmr: Chloramphenicol resistance; DIG: Digoxigenin DNA labeling; GFP: Green fluorescent protein; LB: Luria-Bertan medium; IpaH2: Encoded phosphopantetheinyl transferase; MALDI-TOF: Matrix-assisted laser desorption ionization-time of flight; NRPS: Nonribosomal peptide synthetases; PCR: Polymerase chain reaction; PDA: Potato dextrose agar; PPTase: 4'phosphopantetheinyl transferase; SEM: Scanning electron microscope; Sfp: Encoded phosphopantetheinyl transferase

\section{Acknowledgements}

We would like to thank Prof. Qingxiao Li (University of Hawaii) and Prof. Shujian Zhang (University of Florida) for English language editing. We also thank Mr. Liming Wu (Nanjing Agricultural University) for technical support.
}

\section{Funding}

This work was supported by the National Natural Science Foundation of China (30170623)

\section{Availability of data and materials}

The data sets supporting the conclusions of this article are available upon request.

\section{Authors' contributions}

PJ and HW made substantial contributions to conception, design and acquisition of data; PJ and WL analyze and interpreted data; PJ and HW were involved in drafting the manuscript; WM agreed to be accountable for all aspects of the work in ensuring that questions related to the accuracy. All authors read and approved the final manuscript.

\section{Ethics approval and consent to participate}

Not applicable.

\section{Consent for publication}

Not applicable.

\section{Competing interests}

The authors declare that they have no competing interests.

\section{Publisher's Note}

Springer Nature remains neutral with regard to jurisdictional claims in published maps and institutional affiliations.

Received: 20 June 2017 Accepted: 20 November 2017 Published online: 04 December 2017

\section{References}

1. Ongena M, Jacques P. Bacillus lipopeptides: versatile weapons for plant disease biocontrol. Trends Microbiol. 2008;16(3):115-25. doi:10.1016/j.tim.2007.12.009.

2. Wu L, Wu H, Chen L, Lin L, Borriss R, Gao X. Bacilysin overproduction in Bacillus amyloliquefaciens FZB42 markerless derivative strains FZBREP and FZBSPA enhances antibacterial activity. Appl Microbiol Biotechnol. 2015; 99(10):4255-63. doi:10.1007/s00253-014-6251-0.

3. Stein T. Bacillus subtilis antibiotics: structures, syntheses and specific functions. Mol Microbiol. 2005;56(4):845-57. doi:10.1111/j.1365-2958.2005.04587.x.

4. Kumar A, Sani S, Wray V, Nimtz M, Prakash A, Johri B. Characterization of an antifungal compound produced by Bacillus $s p$. strain $A_{5} F$ that inhibits Sclerotinia sclerotiorum. J Basic Microbiol. 2012;52(6):670-8. 10.1002/jobm. 201100463.

5. Chowdhury S, Uhl J, Grosch R, Alqueres S, Pittroff S, Dietel K, Schmitt K, Borriss R, Hartmann A. Cyclic lipopeptides of Bacillus amyloliquefaciens subsp. plantarum colonizing the lettuce rhizosphere enhance plant defense responses toward the bottom rot pathogen rhizoctonia solani. Mol Plant Microbe In. 2015;28(9):984-95. doi:10.1094/MPMI-03-15-0066-R.

6. Magnet-Dana R, Peypoux F. Iturins, a special class of pore forming lipopeptides: biological and physicochemical properties. Toxicology. 1994;87(1-3):151-74.

7. Vollenbroich D, Özel M, Vater J, Kamp R, Pauli G. Mechanism of inactivation of enveloped viruses by the biosurfactant surfactin from Bacillus subtilis. Biologicals. 1997;25(3):289-97. doi:10.1006/biol.1997.0099.

8. Vollenbroich D, Pauli G, Ozel M, Vater J. Antimycoplasma properties and application in cell culture of surfactin, a lipopeptide antibiotic from Bacillus subtilis. Appl Environ Microb. 1997;63(1):44-9.

9. Seydlová G, Svobodová J. Review of surfactin chemical properties and the potential biomedical applications. Cent Eur J Med. 2008;3(2):123-33. doi:10. 2478/s11536-008-0002-5

10. Tabbene O, Kalai L, Slimene I, Karkouch I, Elkahoui S, Gharboi A, Cosette P, Mangoni M, Jouenne T, Limam F. Anti-Candida effect bacillomycin D-like lipopeptides from Bacillus subtilis B38. FEMS Microbiol Lett. 2011;316(2):10814. doi:10.1111/j.1574-6968.2010.02199.x.

11. Romero D, de Vicente A, Rakotoaly R, Dufour S, Veening J, Arrebola E, Cazorla F, Kuipers $\mathrm{O}$, Paquot M, Pérez-García A. The iturin and fungycin families of lipopeptides are key factors in antagonism of Bacillus subtilis towards Podosphaera fusca. Mol Plant Microbe In. 2007:20(4):430-40. doi:10.1094/MPMI-20-4-0430.

12. Grover M, Nain L, Singh B, Saxena A. Molecular and biochemical approaches for characterization of antifungal trait of a potent biocontrol agent Bacillus subtilis RP24. Curr Microbiol. 2009;60(2):99-106. doi:10.1007/s00284-009-9508-6. 
13. Chen X, Koumoutsi A, Scholz R, Eisenreich A, Schneider $K$, Heinemeyer I, Morgenstern B, Voss B, Hess W, Reva O, Junge H, Voigt B, Jungblut $P$, Vater $J$, Süssmuth R, Liesegang $H$, Strittmatter A, Gottschalk G, Borriss R. Comparative analysis of the complete genome sequence of the plant growth-promoting bacterium Bacillus amyloliquefaciens FZB42. Nat Biotechnol. 2007;25(9):1007-14. doi:10.1038/nbt1325.

14. Mukherjee A, Das K. Correlation between diverse cyclic lipopeptides production and regulation of growth and substrate utilization by Bacillus subtilis strains in a particular habitat. FEMS Microbiol Ecol. 2005;54(3):479-89. doi:10.1016/j.femsec.2005.06.003.

15. Ongena M, Jourdan E, Adam A, Paquot M, Brans A, Joris B, Arpigny J, Thonart P. Surfactin and fengycin lipopeptides of Bacillus subtilis as elicitors of induced systemic resistance in plants. Environ Microbiol. 2007;9(4):108490. doi:10.1111/j.1462-2920.2006.01202.x.

16. Walsh C. Polyketide and nonribosomal peptide antibiotics: modularity and versatility. Science. 2004;303(5665):1805-10. doi:10.1126/science.1094318.

17. Koumoutsi A, Chen XH, Vater J, Borriss R. DegU and YCZE positively regulate the synthesis of bacillomycin D by Bacillus amyloliquefaciens strain FZB42. Appl Environ Microb. 2007;73(21):6953-64. doi:10.1128/AEM.00565-07.

18. Koumoutsi A, Chen X, Henne A, Liesegang H, Hitzeroth G, Franke P, Vater J, Borriss R. Structural and functional characterization of gene clusters directing nonribosomal synthesis of bioactive cyclic lipopeptides in Bacillus amyloliquefaciens strain FZB42. J Bacteriol. 2004;186(4):1084-96. PMID: 14762003

19. Chen X, Koumoutsi A, Scholz R, Borriss R. More than anticipated-production of antibiotics and other secondary metabolites by Bacillus amyloliquefaciens FZB42. J Mol Microb Biotech. 2009;16(1-2):14-24. doi:10.1159/000142891.

20. Tsuge K, Ano T, Hirai M, Nakamura Y, Shoda A. The genes $\operatorname{deg} Q, p p s$ and Ipa-8 (sfp) are responsible for conversion of Bacillus subtilis 168 to plipastatin production. Antimicrob Agents Ch. 1999;43(9):2183-92. PMID:10471562

21. Roongsawang N, Thaniyavarn J, Thaniyavarn S, Kameyama T, Haruki M, Imanaka T, Morikawa M, Kanaya S. Isolation and characterization of a halotolerant Bacillus subtilis BBK-1 which produces three kinds of lipopeptides: bacillomycin L, plipastatin, and surfactin. Extremophiles. 2002; 6(6):499-506. doi:10.1007/s00792-002-0287-2.

22. Jin P, Wang H, Liu W, Fan Y, Miao W. A new cyclic lipopeptide isolated from Bacillus amyloliquefaciens HAB-2 and safety evalution. Pestic Biochem Physiol. 2017; doi:10.1016/j.pestbp.2017.08.015.

23. Wu L, Wu H, Chen L, Yu X, Borriss R, Gao X. Difficidin and bacilysin from Bacillus amyloliquefaciens FZB42 have antibacterial activity against Xanthomonas oryzae rice pathogens. Sci Rep. 2015;5:12975. doi:10.1038/srep12975.

24. Li X, Wu H, Zhang Y, Lu Q, Gao X. Function of degQ and sfp and their effects on fengycin productivity of Bacillus subtilis. Chin J Biol Control. 2015;31:221-8.

25. Sambrook J, Fritsch E, Maniatis T. Molecular cloning: a laboratory manual. Cold Spring Harbor laboratory press. Cold Spring Harbor. 1982;49(1):895-909.

26. Anagnostopoulos C, Spizizen J. Requirements for transformation in Bacillus subtilis. J Bacteriol. 1961;81(5):741-6.

27. Vater J, Kablitz B, Wilde C, Franke P, Mehta N, Cameotra SS. Matrix-assisted laser desorption ionization-time of flight mass spertrometry of lipopeptide biosurfactants in whole cells and culture filtrates of Bacillus subtilis C-1 isolated from petroleum sludge. Appl Environ Microbl. 2002;68(12):6210-9.

28. Pabel $C T$, Vater J, Wilde C, Franke P, Hofemeister J, Adler B, Bringmann G, Hacker J, Hentschel U. Antimicrobial activities and matrix-assisted laser desorption/ionization mass spectrometry of Bacillus isolates from the marine sponge Aplysina aerophoba. Mar Biotechnol. 2003;5:424-34.

29. Leenders F, Stein T, Kablitz B, Franke P, Vater J. Rapid typing of Bacillus subtilis strains by their secondary metabolites using matrix-assisted laser desorption/ionization mass spectrometry of intact cells. Rapid Commun Mass Sp. 1999;13(10):943-9. doi:10.1002/(SICI)1097-0231(19990530)13: 10<943::AID-RCM591>3.0.CO;2-0.

30. Yao S, Gao X, Fuchsbauer N, Hillen W, Vater J, Wang J. Cloning, sequencing, and characterization of the genetic region relevant to biosynthesis of the lipopeptides iturin a and surfactin in Bacillus subtilis. Curr Microbiol. 2003; 47(4):272-7. PMID:14629006

31. Priest F, Goodfellow M, Shute L, Berkeley W. Bacillus amyloliquefaciens sp. nov., nom. rev. Int J Syst Bact. 1987;37(1):69-71. doi:10.1099/00207713-37-1-69.

32. Dunlap C, Kim S, Kwon S, Rooney A. Phylogenomic analysis shows that Bacillus amyloliquefaciens subsp. plantarum is a later heterotypic synonym of Bacillus methylotrophicus. Int J Syst Evol Microbiol. 2015;65(7):2104-9. doi:10. 1099/ijs.0.000226.
33. Dunlap C, Kim S, Kwon S, Rooney A. Bacillus velezensis is not a later heterotypic synonym of Bacillus amyloliquefaciens; Bacillus methylotrophicus, Bacillus amyloliquefaciens subsp. plantarum and 'Bacillus oryzicola' are later heterotypic synonyms of Bacillus velezensis based on phylogenomics. Int J Syst Evol Microbiol. 2016;66:1212-7. https://doi.org/10.1099/ijsem.0.000858

34. Lambalot R, Gehring A, Flugel R, Zuber P, LaCelle M, Marahiel M, Reid R, Khosla C, Walsh C. A new enzyme superfamily: the phosphopantetheinyl transferases. Chem Biol. 1996;3(11):923-36. PMID: 8939709

35. Beld J, Sonnenschein E, Vickery C, Noel J, Burkart M. The Phosphopantetheinyl transferases: catalysis of a posttranslational modification crucial for life. Nat Prod Rep. 2013;31(1):61-108. doi:10.1039/c3np70054b.

36. Reuter K, Mofid M, Marahiel M, Ficner R. Crystal structure of the surfactin synthetase-activating enzyme sfp: a prototype of the $4^{\prime}-$ phosphopantetheinyltransferase superfamily. EMBO J. 1990;18(23):6823-31. PMID:10581256

37. Nakano M, Marahiel M, Zuber P. Identification of a genetic locus required for biosynthesis of the lipopeptide antibiotic surfactin in Bacillus subtilis. J Bacteriol. 1988;170(12):5662-8. PMID: 2848009

38. Huang C, Ano T, Shoda M. Nucleotide sequence and characteristics of the gene, Ipa-14, responsible for biosynthesis of the lipopeptide antibiotics iturin a and surfactin from Bacillus subtilis RB14. J Ferment Bioeng. 1993; 76(6):445-50. doi:10.1016/0922-338X(93)90238-4.

39. Tsuge $K$, Ano T, Shoda A. Isolation of a gene essential for biosynthesis of the lipopeptide antibiotics plipastatin B1 and surfactin in Bacillus subtilis YB8. Arch Microbiol. 1996;165(4):243-51. doi:10.1007/s002030050322.

40. Chen X, Vater J, Piel J, Franke P, Scholz R, Schneider K, Koumoutsi A, Hitzeroth G, Grammel N, Strittmatter A, Gottschalk G, Süssmuth R, Borriss R. Structural and functional characterization of three polyketide synthase gene clusters in Bacillus amyloliquefaciens FZB42. J Bacteriol. 2006;188(11):4024-36. doi:10.1128/JB.00052-06.

41. Hiraoka H, Ano T, Shoda M. Molecular cloning of a gene responsible for the biosynthesis of the lipopeptide antibiotics iturin and surfactin. J Ferment Bioeng. 1992;74(5):323-6. doi:10.1016/0922-338X(92)90068-6.

42. Yao S, Gao X, Fuchsbauer N, Hillen W, Vater J, Wang J. Identification of the genetic region of Bacillus subtilis B3 renders Bacillus subtilis 168 biosynthesis of lipopeptide surfactin positive. Biocontrol Sci Techn. 2003;13(7):691-7. doi: 10.1080/09583150310001606291.

\section{Submit your next manuscript to BioMed Central and we will help you at every step:}

- We accept pre-submission inquiries

- Our selector tool helps you to find the most relevant journal

- We provide round the clock customer support

- Convenient online submission

- Thorough peer review

- Inclusion in PubMed and all major indexing services

- Maximum visibility for your research

Submit your manuscript at www.biomedcentral.com/submit
) Biomed Central 